\title{
A Hybrid Fuzzy Regression - SSA Approach for Electricity Consumption Optimisation
}

\author{
Hannan Amoozad Mahdiraji ${ }^{1}$, Moein Beheshti ${ }^{2}$, Seyed Hossein Razavi Hajiagha ${ }^{3}$, Zenonas \\ Turskis $^{4}$
}

${ }^{1}$ University of Tehran

16th Azar St., Enghelab Sq., Tehran, Iran

E-mail.h.amoozad@ut.ac.ir

${ }^{2}$ University of Tehran Kish International Campus

Niyayesh St., Mirmohanna Blvd., Kish Island, Iran

E-mail.mbeheshti@ut.ac.ir

${ }^{3}$ Khatam University

No.30, Hakim Azam St., North Shiraz St., Mollasadra Ave., Tehran, Iran

E-mail.s.hossein.r@gmail.com

${ }^{4}$ Vilnius Gediminas Technical University

Sauletekio av. 11, 10223 Vilnius, Lithuania

E-mail.zenonas.turskis@vgtu.lt

cross $^{\text {ref }}$ http://dx.doi.org/10.5755/j01.ee.30.2.21001

\begin{abstract}
The critical impact of electricity on the quality of human life and the use of all electrical appliances and equipment is in principle self-evident. Nevertheless, governments cannot afford even productivity to consumption. The countries developed many structures to operate and improve the city and industrial electricity consumption and to manage power generation efficiency. Increase in population and the culture of consumption force the governments to raise the price. However, it is difficult to find ways and means to effectively manage trends in public behaviour and to control the harmful action of the population. This process requires knowing the need and consumption of electricity. The article discusses the primary criterion that influences electricity consumption and uses the singular spectrum analysis based on these factors to predict use. Besides, a fuzzy regression model is represented to optimise function. Results of optimisation show a considerable reduction in comparison with SSA forecasting method, indicating the efficiency of the offered method. Eventually results considerably assume that attention to a way of construction and improvements of the culture of use is a priority of the persons making decisions to reduce radical electric consumption in Iran and to become more optimistic concerning management of an electrical network.
\end{abstract}

Keywords: Singular Spectrum Analysis; Electrical Demand; Electrical Energy Consumption; Fuzzy Regression; Prediction.

\section{Introduction}

Electrical power is an inevitable part of the sustainable development of countries. Measuring business cycles provides a reference point for assessing macroeconomic theory and policy (Skare \& Stjepanovic, 2016). Economic expansions and slowdowns are inherent in modern financial systems and impact energy and resources consumptions. The problems involve a multitude of requirements and uncertain conditions that have to be taken into consideration simultaneously (Hashemkhani Zolfani et al., 2013). Economic, social and ecological components of development have both direct and reverse impacts (Ginevicius et al. 2018). An appropriate choice at an early stage of a project is crucial regarding adding value over scope, time and total investment strategic decisions (Saparauskas et al., 2011). Analysis helps to rate the electricity generation technologies and consumption considering their economic, technological, environmental social and political aspects (Medineckiene $e t$ al., 2015; Streimikiene et al., 2016). Researchers proposed dozens of different utility aggregation functions for the resolution of similar problems by employing multi-criteria as an aid (Zavadskas et al., 2015c; Bagocius et al., 2014; Zavadskas et al., 2015a; 2015b; 2015c).

Consumption and production are two dynamically changing life-changing sides and depends on dozens of factors (Zavadskas et al., 2009). Consumption as a mean to satisfy ones' needs has been investigated mainly by using economic and psychological approaches (Taujanskaite et al., 2015). The amount of effective used electricity amount indicates the economic prosperity of nations (Tunc et al., 2006). Shiu \& Lam (2004) investigated the relationship between electricity consumption and economic growth and found out that the electricity usage increases the amount of GDP. Due to the increase of urbanisation besides the industries EC needs to be monitored and reduced (Pampuri et al., 2016).

Figure 1 shows the rate of electricity consumption (EC) comparison between countries in kWh from 1990 to 2012. Arab countries in the Middle East, like UAE, are consuming electrical power more than Iran. Nonetheless, the pestilent point is that all four considered countries are emphasising to 
reduce the consumption rate and conspicuously is evident that a declination path in these countries policies is in progress. Iran's strategy is to subsidise electricity for consumers, to buy the produced power from the private sector and provide it to the final consumer as a support act (BEEP, 2011). Besides the industrial usage, the residential sector and buildings are responsible for $33.2 \%$ of Iran's EC. Considering a $41 \%$ growth of this section usage since 1989 and a $7.9 \%$ growth rate of total per capita EC besides of 3.3 $\%$ of global concerns us to control and predict Iran's EC, otherwise, by the next decade Iran may face a devastating situation of EC by two times (Pourazarm \& Cooray, 2013). A growing trend highlights the need to integrate environmental sustainability into efforts related to new product development, energy consumption, and resources use. It is even operating in different countries and sectors, an essential driver for the proper choice (Jugend et al., 2017). However, their short-run economic performance does not correspond to the observed business cycles of other global emerging markets. The business cycles of these countries are longer and more pronounced their recessions. Economic activity in the studied countries is relatively low and volatile, and the trade balance and government purchases have a relatively significant countercyclical character (Szomolanyi et al., 2017). To manage the development of regions and thus reduce the social tensions in the country, we need to be able to assess the state of the main components of sustainable development (economic, social and ecological development) at a certain period in time, as well as to determine their interrelationships.

The use of quantitative criteria limits the influence of subjective, non-economic factors on consumption-related resource management and can positively affect its efficiency. Processes and phenomena vary significantly according to the nature of many qualities - physical, chemical, social, and others. The need for the development of socioeconomic systems also arises since they are open; thus, they exposed continuously to the changing environment (Ginevicius et al., 2018). Selection of the appropriate management options for a definite machining requirement observed as multi-criteria decision-making (MCDM) problem with different criteria. Chatterjee et al. (2017) proposed a novel hybrid method encompassing factor relationship (FARE) (Ginevicius, 2011) and multi-attributive border approximation area comparison (MABAC) methods to select and evaluate feasible alternatives (Pamucar et al., 2015).

Typically, the study of market behaviour under the demand and supply law graphically represented by the traditional demand and supply curves embodied in twodimensional graphs. Meanwhile, multidimensional realtime dynamic economic behaviour (including consumption) is a problem that affects market behaviour. The 2dimensional and 3-dimensional spaces not able to capture the action of the real industrial world as a whole. It is clear that the real world is continually changing and inside the Mega-Space or Universe, the number of General-Spaces, Sub-Spaces, Micro-Spaces, Nano-Spaces and JI-Spaces. All these spaces move differently and across time. Besides, Ruiz Estrada et al. (2016) mentioned the roles of Euclidian geometry and Minkowski's n-dimensional spaces (Einstein, 1961) supporting this proposition. One of the common challenges that exist throughout the World is to compiling, distribution, and sharing of knowledge ready for practice as a critical element for socio-economic development and progress acceleration (Ziemianczyk et al., 2017).

Scholars have presented both linear and non-linear approaches to overcome EC crisis. Kermanshahi (1998) forecasted a long term load of the total power demand amount, Abdel-Aal (2006) investigated electric daily peak loads using abductive networks. Kermanshahi \& Iwamiya (2002) used two different artificial neural networks for longterm load forecasting. Buhari \& Adamu (2012) forecasted a short term load using an artificial neural network. Scholars have furthermore implemented the important heuristic approaches like a genetic algorithm. Ozturk et al. (2004) suggested a generic algorithm notion of estimating EC of residential-commercial sectors, while Canyurt et al. (2007) modelled and applied Genetic Algorithm approach to predict the future total energy input values.

Engineers, based upon their ability and experience to design, analyse, and synthesise (Arabzad et al., 2015), play a vital role in capital investment decisions (Karaulova \& Bashkite, 2016). The proposed model y determines and forecasts electricity consumption in Iran by employing a hybrid approach consisting of Singular Spectrum Analysis (SSA) in conjunction with fuzzy regression methodology to optimise the fitness function. This model enables them to design suitable policies to prevent any possible disaster or ascending trend in power usage. The remainder of the research is organised as follow. Initially SSA methodology and related steps and formulas have been considered; afterwards, the methodology's preliminaries compromising fuzzy concepts are finalised. Consequently, fuzzy regression and its essential foundations are introduced; furthermore, by proposing the optimisation model, the electricity consumption will be controllable. The proposed approach is applied to Iran electricity consumption, and the related objective function is emanated, and by employing a fuzzy optimisation approach, the desired decision variables to achieve minimum electricity consumption are obtained.

\section{Singular Spectrum Analysis (SSA)}

The first principles of SSA emerged in the scene of forecasting methods by Broomhead \& King (1986) and Pike et al. (1984) works, and since then the non-parametric method is proved to be an accurate method. Hassani (2007) investigated this model and compared it with Box-Jenkins SARIMA models, the ARAR and the Holt-Winter algorithm. One of the critical features of this technique is that the prediction is deployed without prior knowledge of the underlying structure (Ghanati 2016; Zhigljavsky 2011; Chu et al., 2014). Many scholars have accepted the uppermost prediction technique. Carniel et al. (2006) performed SSA to improve Nakamura spectral ratios. Ghaderi et al. (2011) applied SSA to Localize heart sounds in respiratory. As a case in point, an investigation on UK tourism income concluded SSA is outperforming. SARIMA is another proof of this methods validity (Beneki et al., 2012). Golyandina \& Korobeynikov (2014) described the availing $\mathrm{R}$ package for SSA. There is a finite number of SSA-fuzzy researches. Abdollahzade et al. (2015) investigated a local linear neuro-fuzzy model and optimised 
singular spectrum analysis method to forecast nonlinear and chaotic time series. Furthermore, Xiao et al. (2014) combined singular spectrum analysis, adaptive-networkbased fuzzy inference system and improved particle swarm optimisation to forecast air transport demand.

SSA consists of two parts: Decomposition \& Reconstruction (Hassani \& Mahmoudvand, 2013). The two choices referred to as window length $L$ and number of eigenvalues $r$, and each of these stages comprises two steps called Embedding, Singular Value Decomposition (SVD) and grouping and diagonal averaging. The rest of methodology has been mainly taken from (Chang et al., 2015; Plaza \& Lopez, 2017; Hassani, 2007; Hassani et al., 2015; Maddirala \& Shaik, 2016). The first step presents mapping the original single dimension time series to multidimensional lagged vectors. Assuming $u_{m}[n]$ as an observed data from the $m^{\text {th }}$ channel at the $n^{\text {th }}$ time step, then the $u[n]$ vector is defined as below:

$$
u[n]=\left[\begin{array}{c}
u_{1}[n] \\
u_{2}[n] \\
\vdots \\
u_{M}[n]
\end{array}\right], n=1 \sim N
$$

Considering $N$ as the number of sampling points, the $U$ matrix is embedded with a raw size of $M L$ and column size $k$ as follows:

$$
U=\left[\begin{array}{cccc}
u[1] & u[2] & \cdots & u[k] \\
u[2] & u[3] & \cdots & u[k+1] \\
\vdots & \vdots & \ddots & \vdots \\
u[L] & u[L+1] & \cdots & u[N]
\end{array}\right] k
$$

The matrix $U$ is defined as the trajectory matrix being a Henkel matrix formed as $\left(U_{i j}\right)_{i, j=1}^{L, k} \cdot u_{i}$ is the $L$-lagged vectors. It is worth noting here that, the parameter $L$ refers to the window length, this is one of the most critical choices in the process of SSA methodology as the condition of signal decomposition results depends on this factor (García Plaza \& Núnez Lopez, 2017). With this fact in mind, remark that choosing the window length too long provides more detailed signal analysis but hinders the identification of trend components, the dynamic elements, and the noise components from the original signal. Although narrowing the amount of the $L$ value simplifies the analysis; nonetheless, there might be a lack of principle component resulting deficient signal decomposition. Maddirala \& Shaik (2016) pointed out that criteria $L$ are chosen upon the criteria $M>\frac{f_{s}}{f}$, where $f_{s}$ is supposed as a sampling frequency while $f$ is the frequency of the signal of interest. This stage is the embedding stage. This procedure forms $k$ lagged vectors $(k=N-L+1)$ and maps the time series with length $N$ to an $M L$ time-delay series with length $k$ (Bozzo et al., 2010).

Decomposing the trajectory matrix into a unit-rank elementary matrix $U_{i}$ using singular value decomposition.

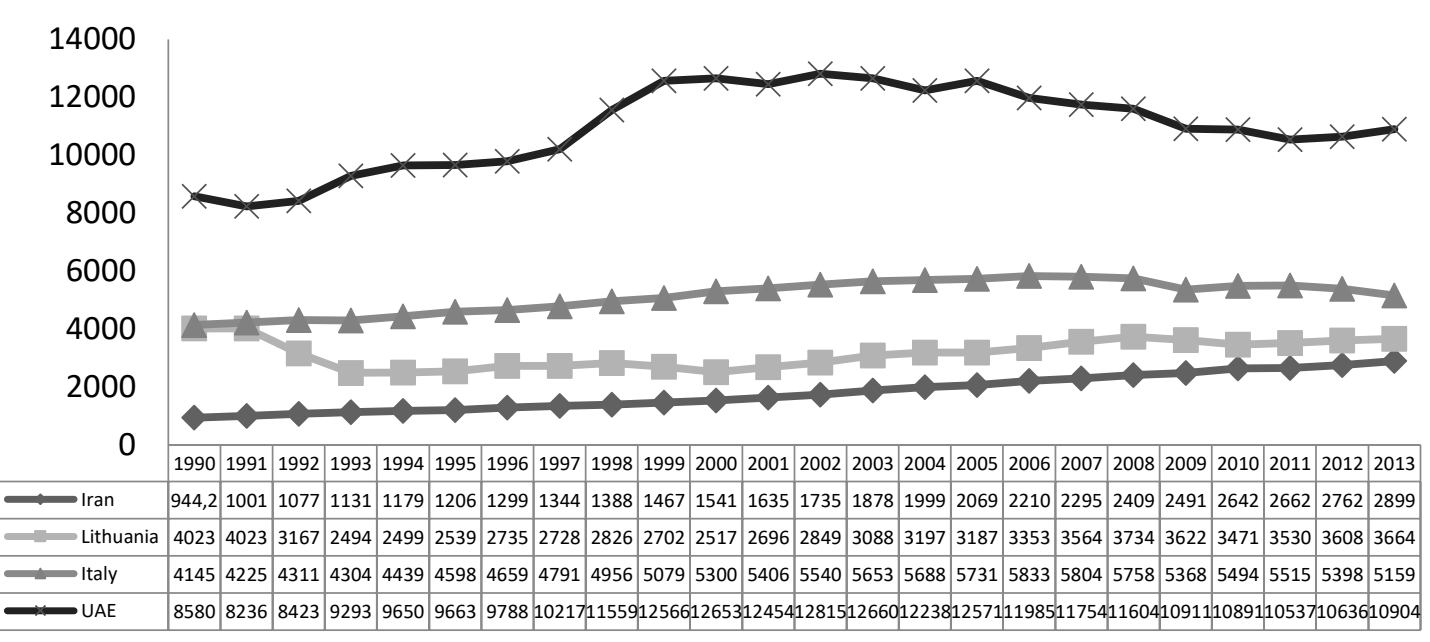

Figure 1. Electricity Consumption per capita (kWh) (Source: The World Bank)

(SVD) is the next step. The decomposition procedure is from the calculated eigenvalues $\left(\lambda_{i}\right)$ and eigenvectors $\left(\theta_{i}\right)$ of a matrix $P$ of dimension $L \times L$ defined by the expression $P=U U^{T}$. The trajectory matrix is determined by the sum of elementary matrices $U=\sum_{i=1}^{d} U_{i}$, where $U_{i}=$ $\sqrt{\lambda_{i}} \theta_{i} V_{i}^{T}(i=1, \ldots, d), V_{i}=U^{T} \theta_{i} / \sqrt{\lambda_{i}}$ and the rank of $U$, $d=\max \left\{i, \lambda_{i}>0\right\}$. The matrices $U_{i}$ are elementary matrices as they have rank 1 . The collection $\left(\sqrt{\lambda_{i}}, \theta_{i}, V_{i}\right)$ is called the $i$-th Eigen triple of the matrix $U, \sqrt{\lambda_{i}}(i=1, \ldots, d)$ are the singular values of the matrix $U$ and the set $\left\{\sqrt{\lambda_{i}}\right\}$ is considered to be the spectrum of the matrix U. by the mean of the equation $A=\lambda_{i} / \sum_{i=1}^{d} \lambda_{i}$ the weight of each matrix $U_{i}$ on the trajectory matrix $U$ from their associated eigenvalues is figured. The graphical designation of the specific weight of the eigenvalues $(A)$ in decreasing order of magnitude $\left(\lambda_{1} \geq \lambda_{2} \geq \cdots \geq \lambda_{L}\right)$ is the singular spectrum.

In toward the second stage of SSA methodology, an individual or grouping analysis is performed to reconstruct the elementary matrices $U_{i}$ and to do so, we split the $U_{i}$ s into several groups and sum the matrices within each group. Designating $I=\left\{i_{1}, \ldots, i_{p}\right\}$ as a group of indices $i_{1}, \ldots, i_{p}$, then the matrix $U_{I}$ which corresponds to the group $I$, is interpreted as $U_{I}=U_{i 1}+\cdots+U_{i p}$. The split of the set of indices $J=1, \ldots, d$ into the disjoint subsets $I_{1}, \ldots, I_{m}$ corresponds to the representation. 
Hannan Amoozad Mahdiraji, Moein Beheshti, Seyed Hossein Razavi Hajiagha, Zenonas Turskis. A Hybrid Fuzzy...

$U=U_{I 1}+\cdots+U_{I m}$

One of the decisive points in the SSA approach is the selection of the indices $I_{m}$. García Plaza \& Núnez Lopez (2017) point, that the incorrect choice of indices leads to principal components that do not contain prominent processing data of providing redundant data. The nominating procedure of sets $I_{1}, \ldots, I_{m}$ is denominated as the Eigen triple grouping. The share of the equal eigenvalues $\sum_{i \in I} \lambda_{i} / \sum_{i=1}^{d} \lambda_{i}$ measures the benefaction of the component $U_{I}$ for a given group $I$.

The reconstruction stage maps the estimated trajectory matrix of the signal of interest into a single channel signal. Presume $\hat{a}_{k j}$ as an element positioned in the $k$ th row and the $j$ th column of the trajectory matrix, then for a single channel motion artefact signal like $\hat{a}(n)$ the mathematical expressions are defined by $f_{k}=\left(f_{k}^{1}, f_{k}^{2}, f_{k}^{3}\right)$, where we calculate elements of the series for $1 \geq n<L$ by $f_{k}^{1}$ and for $L \geq n \leq k$ we implement $f_{k}^{2}$. Finally, we use $f_{k}^{3}$ for $k<$ $n \leq N$ (Eq.4).

$$
\hat{a}(n)=\left\{\begin{array}{c}
f_{k}^{1}=\frac{1}{n} \sum_{k=1}^{n} \hat{a}_{k, n-k+1} \\
f_{k}^{2}=\frac{1}{L} \sum_{k=1}^{L} \hat{a}_{k, n-k+1} \\
f_{k}^{3}=\frac{1}{N-n-1} \sum_{k=n-k+1}^{N-k+1} \hat{a}_{k, n-k+1}
\end{array}\right.
$$

\section{Fuzzy Set Theory Preliminaries}

Fuzzy sets introduced by (Zadeh, 1965) is an efficient and accurate tool in uncertain circumstances (Zimmermann, 1978). Scholars have employed it in many cases (Mahdiraji et al., 2016; Razavi et al., 2015; Razavi et al., 2013). A complete review of Fuzzy sets and its applications can be found in (Buckley \& Eslami, 2002; Masulli et al., 2007; Wang, 1983); however, a review of basic sets is briefed in the rest of this section.

A presumed fuzzy number like $D$ can be delineated as an interval $\left[q_{l}, q_{u}\right]$. The apparent fact is that $q_{l}$ is the lower boundary of $D$ and $q_{u}$, the upper. Respectively $\bar{q}_{\alpha}^{L}$ and $\bar{q}_{\alpha}^{U}$ are outlined as (Wang 2015):

$$
\begin{aligned}
& \bar{q}_{\alpha}^{L}=\inf (z)_{\mu_{\bar{q}}(z) \geq \alpha} \\
& \bar{q}_{\alpha}^{U}=\sup (z)_{\mu_{\bar{q}}(z) \geq \alpha}
\end{aligned}
$$

Here for any $q \in(0,1], F(\mathbb{R})$ is the set of fuzzy numbers and $\left[\bar{q}_{\alpha}^{L}(0), \bar{q}_{\alpha}^{U}(0)\right]=q_{0}$.

For any fuzzy number like $\bar{q}$, (Heilpern 1992) defines the expected interval $E I(\bar{q})$ and expected value $E V(\bar{q})$ as below:

$$
\begin{aligned}
& E I(\bar{q})=\left[E_{*}(\bar{q}), E^{*}(\bar{q})\right]=\left[\int_{0}^{1} \bar{q}_{\alpha}^{L}(\beta) d \beta, \int_{0}^{1} q_{\alpha}^{U}(\beta) d \beta\right] \\
& E V(\bar{q})=\frac{1}{2}\left(E_{*}(\bar{q})+E^{*}(\bar{q})\right)
\end{aligned}
$$

ambiguity $A m b(\bar{q})$, value $\operatorname{Val}(\bar{q})$, width $w(\bar{q})$, left-hand ambiguity $A m b_{L}(\bar{q})$, right-hand ambiguity $A m b_{U}(\bar{q})$ were investigated by (Delgado et al., 1998; Grzegorzewski 1998). Grzegorzewski (1998) defined one of the eminent matrices in fuzzy sets, the Euclidean distance as:

$$
\begin{aligned}
d^{2}(\bar{q}, \bar{p})=\int_{0}^{1}\left(\bar{q}_{\alpha}^{L}(\beta)\right. & \left.-\bar{p}_{\alpha}^{L}(\beta)\right)^{2} d \beta \\
& +\int_{0}^{1}\left(\bar{q}_{\alpha}^{U}(\beta)-\bar{p}_{\alpha}^{U}(\beta)\right)^{2} d \beta
\end{aligned}
$$

Literature review suggests that scholars implement triangular and trapezoidal sets to investigate fuzzy numbers, wherein this research considers trapezoidal numbers; therefore, by reviewing trapezoidal fuzzy numbers (henceforth $\operatorname{TrFN}$ ), main operations and illustrating its schematic view in Figure 2, the section is finalised.

0

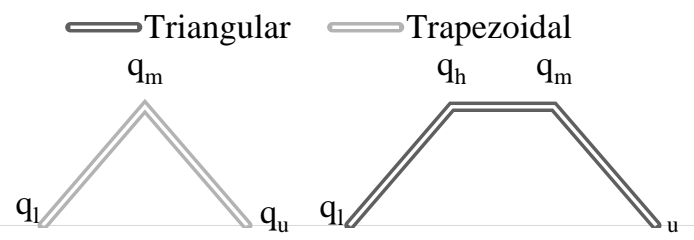

Figure 2. Schematic View of Triangular and Trapezoidal Source: Own

Chen \& Chen (2007) and Kumar \& Gupta (2011) designate the arithmetic operations on two $\operatorname{TrFN} \bar{q}=$ $\left(q_{l}, q_{h}, q_{m}, q_{u}\right)$ and $\bar{p}=\left(p_{l}, p_{h}, p_{m}, p_{u}\right)$ as follow:

$$
\begin{aligned}
& \lambda \geq 0, \lambda \bar{q}=\left(\lambda q_{l}, \lambda q_{h}, \lambda q_{m}, \lambda q_{u}\right) \\
& \lambda \leq 0, \lambda \bar{q}=\left(\lambda q_{u}, \lambda q_{m}, \lambda q_{h}, \lambda q_{l}\right) \\
& \bar{q}+\bar{p}=\left(q_{l}+p_{l}, q_{h}+p_{h}, q_{m}+p_{m}, q_{u}+p_{u}\right) \\
& \bar{q}-\bar{p}=\left(q_{l}-p_{u}, q_{h}-p_{m}, q_{m}-p_{h}, q_{u}-p_{l}\right)
\end{aligned}
$$

\section{Fuzzy Linear Regression}

Regression analysis is applied to study the relation among an affected variable, called the dependent variable, with a set of affecting variables, called independent variables. The linear regression model can be displayed as: $Y_{i}=\beta_{0}+\beta_{1} X_{i 1}+\beta_{2} X_{i 2}+\cdots+\beta_{k} X_{i, k}+\varepsilon_{i}$

For $i=1,2, \ldots, n$, where $Y=\left[Y_{1}, Y_{2}, \ldots, Y_{n}\right]^{t}$ is the vector of dependent variables and $X=\left[X_{1}, X_{2}, \ldots, X_{n}\right]$ is the matrix of independent variables with $X_{j}=$ $\left[X_{1 j}, X_{2 j}, \ldots, X_{n j}\right]^{t}, j=1,2, \ldots, k$ as the vector of $j$ th independent variable. Also, $\varepsilon_{i}$ are independent normal variables with $E\left(\varepsilon_{i}\right)=0$ and $\operatorname{Var}\left(\varepsilon_{i}\right)=\sigma^{2}$. The least square estimation of coefficients vector $\beta=$ $\left[\beta_{0}, \beta_{1}, \beta_{2}, \ldots, \beta_{k}\right]^{t}$ is obtained as

$\beta=\left(X^{t} X\right)^{-1} X^{t} Y$

where

$X=\left[\begin{array}{cccc}1 x_{11} & \cdots & x_{1 k} \\ 1 x_{21} & \cdots & x_{2 k} \\ \vdots & \vdots & \ddots & \vdots \\ 1 x_{n 1} & \cdots & x_{n k}\end{array}\right]$

In ordinal regression, both dependent and independent variables are crisp. However, in a world of uncertain events, usually, the information is unknown and are determined vaguely. Therefore, fuzzy regression analysis is proposed to examine the problem of the relationship among several variables in a fuzzy environment. Tanaka et al. (1982) initiated the topic of fuzzy linear regression. The issue is later extended and studied by scholars. Based on Ubale \& Sananse (2015) investigation on fuzzy regression application and literature review, Chen et al. (2004) 
Arulchinnappan \& Rajendran (2011), Abdullah \& Zamri (2012), Pushpa \& Vasuki (2013), Shafi \& Rusiman (2015), Muzzioli et al. (2015), and Chen et al. (2016), are among the most illustrious recent jobs on this topic.

The problem considered in this paper is to estimate a function of electricity consumption with fuzzy regression; therefore, the $\mathrm{Wu}$ (2003) proposed method is applied to determine the corresponding function. In this method, an $\alpha$ level set $\left(\tilde{\hat{\beta}}_{j}\right)_{\alpha}$ is computed for each regression coefficient as follow:

$$
\left(\tilde{\hat{\beta}}_{j}\right)_{\alpha}=\left[\left(\tilde{\hat{\beta}}_{j}\right)_{\alpha}^{L},\left(\tilde{\hat{\beta}}_{j}\right)_{\alpha}^{U}\right]
$$

To this end, $\mathrm{Wu}$ (2003) proposed that first, the $\alpha$-level sets of dependent and independent variables are computed. Supposing these sets as $\left[(\tilde{X})_{\alpha^{\prime}}^{L}(\tilde{X})_{\alpha}^{U}\right]$ and $\left[(\tilde{Y})_{\alpha^{\prime}}^{L},(\tilde{Y})_{\alpha}^{U}\right]$, two regression functions are fitted on $\left[(\tilde{X})_{\alpha}^{L},(\tilde{Y})_{\alpha}^{L}\right]$ with $B_{1}$ coefficients vector and $\left[(\tilde{X})_{\alpha}^{U},(\tilde{Y})_{\alpha}^{U}\right]$ with $B_{2}$ coefficients vector. Afterwards, the interval regression coefficient at confidence level $\alpha$ is defined as:

$$
\begin{aligned}
\left(\tilde{\hat{\beta}}_{j}\right)_{\alpha}=\left[\left(\tilde{\hat{\beta}}_{j}\right)_{\alpha}^{L},\right. & \left.\left(\tilde{\hat{\beta}}_{j}\right)_{\alpha}^{U}\right] \\
& =\left[\min \left(B_{1}, B_{2}\right), \max \left(B_{1}, B_{2}\right)\right]
\end{aligned}
$$

\section{Proposed Structure}

The proposed model is hinged on an SSA/Fuzzyregression approach to discuss and optimise the electric power consumption in Iran. At the first phase experts suggested primary criterions as the main concern to be addressed in our research, and by the further interviews with economic and energy experts, besides analysing demographics of Iran, mentioned criterions were reduced to principal objects to be examined. Relative and discord data of those criterions in the second phase were gathered and applied by the SSA approach to reduce noise and forecast the next 15 years' behaviour. Consequently, Fuzzyregression method was scheduled to determine the power consumption function based on independent variables. Eventually, the objective function subjected to governmental policies is optimised. Figure 3 demonstrates the main steps of our proposed approach.

\section{Iran's Electricity Consumption Evaluation}

Phase 1: Preparation. The expert's suggestions gathered the critical criterions in Power consumption. Table 1 illustrates the primal data list, comprising criteria's description (input variables), quantitative or qualitative type of variables and positive or negative influence of each input variable on electricity consumption. Further interviews with economic and energy experts in conjunction with analysing demographics of Iran in brainstorming sessions, lead us to a narrower chose of criterions and five targets were picked from Table 1. Table 2 demonstrates the final criteria (input variables) choice. The discord data in the above table and related data of electrical consumption in Iran present the main objects to implement in Fuzzy-regression optimisation approach.
Table 1

Initial Criteria (Initial Input Variables)

\begin{tabular}{|llll|}
\hline No. & Criteria description & Type & Effect \\
\hline 1 & Home appliance technology level & Quantitative & + \\
2 & $\begin{array}{l}\text { Population growth rate } \\
3\end{array}$ & Quantitative & - \\
4 & Undustrial development state & Quantitative & - \\
& Alternative energy sources & Quant./ & - \\
5 & $\begin{array}{l}\text { Qubstitution option } \\
6\end{array}$ & Qualitative & + \\
7 & $\begin{array}{l}\text { Electricity price share from the } \\
\text { household expense }\end{array}$ & Quantitative & + \\
8 & $\begin{array}{l}\text { Iran's population structure } \\
9\end{array}$ & Quantitative & + \\
10 & $\begin{array}{l}\text { implementation } \\
\text { Energy Productivity in Iran }\end{array}$ & Qualitative & + \\
11 & Proper timing and supplement & Qualitative & + \\
& usage & Qualitative & + \\
\hline
\end{tabular}

(Source: Own)

Thus, related data were gathered from official databases encompassing Statistical Centre of Iran, Iran Ministry of energy, National Iranian Productivity Organization and Central Bank of Iran, uncovering electrical consumption rate in the last 20 years (presented in Table 3).

\begin{tabular}{|c|c|c|c|}
\hline No. & Criteria description & Type & Effect \\
\hline 1 & Power consumption price & Quantitative & + \\
\hline 2 & Population growth rate & Quantitative & - \\
\hline 3 & $\begin{array}{l}\text { Modern } \\
\text { implementation }\end{array}$ & Qualitative & + \\
\hline 4 & Energy Productivity in Iran & Quantitative & + \\
\hline 5 & $\begin{array}{l}\text { Proper timing and supplement } \\
\text { usage }\end{array}$ & Qualitative & + \\
\hline
\end{tabular}

Table 2

Final Criteria Selection

(Source: Own)

Table 3

Iranian Electrical Consumption in the Last 20 Years

\begin{tabular}{|cccc|}
\hline Year & $\begin{array}{c}\text { Consumption/Million } \\
\text { KWh }\end{array}$ & Year & $\begin{array}{c}\text { Consumption/Million } \\
\text { KWh }\end{array}$ \\
\hline 1996 & 65854 & 2006 & 132897 \\
1997 & 69671 & 2007 & 144598 \\
1998 & 73358 & 2008 & 152330 \\
1999 & 77646 & 2009 & 161445 \\
2000 & 84656 & 2010 & 168438 \\
2001 & 90336 & 2011 & 184182 \\
2002 & 97171 & 2012 & 183905 \\
2003 & 105076 & 2013 & 194148 \\
2004 & 114625 & 2014 & 203088 \\
2005 & 124466 & 2015 & 219653 \\
\hline
\end{tabular}

(Source: Mentioned Databases)

The population growth rate, energy productivity criteria and power costs are denoted in Table 4. Data for 2016 and 2017 are not yet prepared at the time of developing the research. These two years were forecasted; however, considering the publication time, results for 2016 and 2017 were deleted by the authors. 
Hannan Amoozad Mahdiraji, Moein Beheshti, Seyed Hossein Razavi Hajiagha, Zenonas Turskis. A Hybrid Fuzzy...

Table 4

Total Population, Energy Productivity, Cost

\begin{tabular}{|cccc|}
\hline Year & $\begin{array}{c}\text { Population } \\
\text { Growth rate } \\
\text { ( Million) }\end{array}$ & $\begin{array}{c}\text { Power cost } \\
\text { (IRR/KWh) }\end{array}$ & $\begin{array}{c}\text { Energy Productivity } \\
\text { criteria (in billions of } \\
\text { euros of GDP per } \\
\text { exajoule on energy } \\
\text { consumed) }\end{array}$ \\
\hline 1996 & 61306632 & 6 & 118 \\
1997 & 62426086 & 6 & 128 \\
1998 & 63616065 & 8 & 106 \\
1999 & 64780362 & 8 & 113 \\
2000 & 65850062 & 9 & 109 \\
2001 & 66812736 & 10 & 108 \\
2002 & 67696677 & 10 & 88 \\
2003 & 68522074 & 10 & 75 \\
2004 & 69321953 & 12 & 123 \\
2005 & 70122115 & 14 & 75 \\
2006 & 70923164 & 14 & 93 \\
2007 & 71720859 & 16 & 111 \\
2008 & 72530693 & 18 & 117 \\
2009 & 73370982 & 18 & 91 \\
2010 & 74253373 & 36 & 100 \\
2011 & 75184322 & 36 & 129 \\
2012 & 76156975 & 36 & 96 \\
2013 & 77152445 & 49 & 103 \\
2014 & 78143644 & 50 & 117 \\
2015 & 79109272 & 53 & \\
\hline
\end{tabular}

(Source ${ }_{1}$ : World Bank, Source 2: Ministry of Energy, Source 3 : National Iranian Productivity Organization)
Phase 2: SSA Implementation. The window length of time series is set as $L=10$, and the variables were grouped based on their dispersion and eigenvalues. Afterwards, the time series was reconstructed and employed to forecast the next 15 years. Table 5 demonstrates the reconstructed time series. Moreover, Table 6 illuminates the forecast of electricity consumption criterions between 2016 and 2030. It is worth noting here that SSA implementation, reconstruction of time series, noise reduction of time series and SSA forecasts of the response variable and all input variables were calculated by Caterpillar SSA software.

Phase 3: Estimation. The fuzzy regression method of $\mathrm{Wu}$ (2003) is applied to estimate the amount of energy consumption. The below function is calculated from the observed data using this method, and the results presented in Table 7.

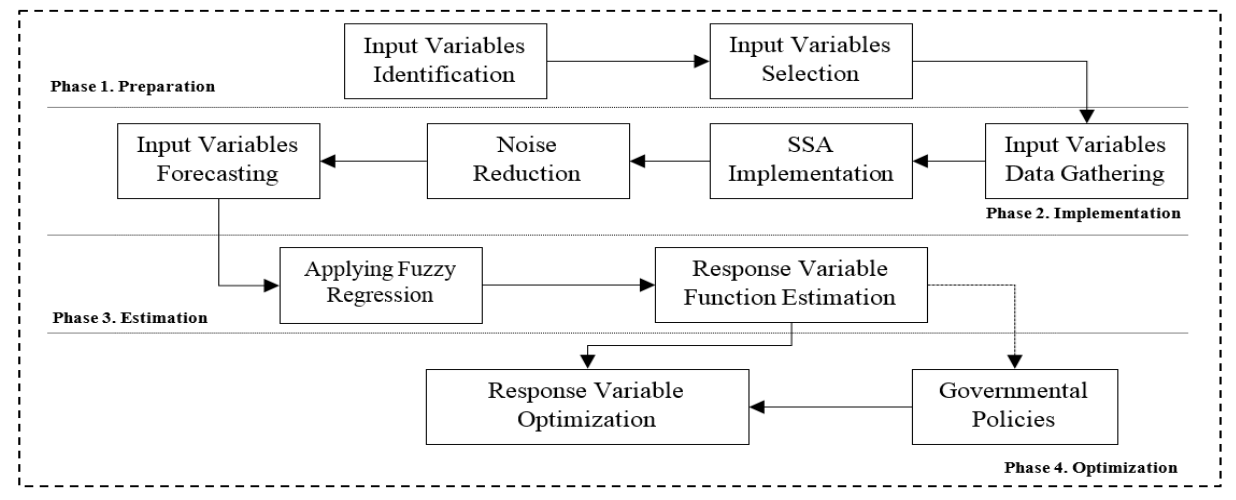

Figure 3. Proposed Approach

(Source: Own)

$$
\begin{array}{r}
{\left[\underline{C}_{t}, \bar{C}_{t}\right]=[-398718,-398235]+771 P r_{t}} \\
+198 P o_{t}+0.00708 P o_{t} \\
-142 C M_{t}-2272 U C_{t}
\end{array}
$$

Response variable prediction, input variables prediction and qualitative variables are required to estimate electricity consumption, $r$. Furthermore, to consider uncertain information and fuzzy logic, based on qualitative forecasting method (specifically Delphi method) the future behaviour of construction and usage culture of electricity power in Iran were emanated. The results are presented upon linguistic terms, observable in Table 7.

Phase 4: Optimisation. The fitted model is an approximation of electricity consumption in Iran. This model can be used to predict consumption as a function of independent variables. However, to propose an optimisation model of whether to improve the consumption of Iran, an optimisation model is formulated in this section. The proposed optimisation model seeks to find the way of decreasing yearly $5 \%$ of electricity consumption in Iran in a period between 2017 to 2020 .
In fact, $\left[\underline{C}_{t+1}^{*}, \bar{C}_{t+1}^{*}\right] \in 0.95\left[\underline{C}_{t}, \bar{C}_{t}\right]$. Ishibuichi \& Tanaka (1990) suggest that $[\underline{A}, \bar{A}] \leq[\underline{B}, \bar{B}]$ if $\bar{A} \leq \bar{B}$ and $(\underline{A}+\bar{A}) \leq$ $(\underline{B}+\bar{B})$. Following Ishibuichi \& Tanaka (1990), the inequality is transformed into two equivalent inequalities:

Table 5

The Reconstructed Time Series

\begin{tabular}{|ccccc|}
\hline Year & Price & Productivity & Consumption & Population \\
\hline 2005 & 13.6 & 99.05 & 121996.81 & 69975504 \\
2006 & 14.76 & 97.83 & 130169.63 & 70855181.3 \\
2007 & 18.05 & 103.14 & 139295.83 & 71758274.2 \\
2008 & 20.01 & 103.44 & 148794.35 & 72651258.2 \\
2009 & 22.39 & 105.31 & 158665.69 & 73537926.9 \\
2010 & 30.5 & 97.49 & 168843.49 & 74424126.6 \\
2011 & 34.2 & 105.20 & 179414.61 & 75316196.9 \\
2012 & 36.97 & 115.77 & 189851.74 & 76219381.3 \\
2013 & 47.91 & 100.97 & 200700.45 & 77137065.5 \\
2014 & 51.8 & 107.25 & 211941.98 & 78070467.7 \\
2015 & 50.6 & 121.24 & 224175.53 & 79018774.3 \\
\hline
\end{tabular}

(Source: Own; Software Caterpillar SSA) 
Forecasted Criterions in the Period of 2016-2030

\begin{tabular}{|ccccc|}
\hline Year & Price & Productivity & Consumption & Population \\
\hline 2018 & 83.03 & 115.7 & 270756.46 & 81996472.8 \\
2019 & 104.12 & 115.34 & 287392.10 & 82995083.4 \\
2020 & 130.27 & 115.87 & 305010.31 & 84006902.4 \\
2021 & 136.11 & 114.32 & 323687.35 & 85032749.9 \\
2022 & 158.16 & 120.64 & 343565.60 & 86072956.1 \\
2023 & 197.10 & 120.02 & 364746.89 & 87127512.6 \\
2024 & 211.62 & 115.92 & 387347.57 & 88196275 \\
2025 & 238.3 & 123.1 & 411437.13 & 89279173.6 \\
2026 & 299.38 & 122.53 & 436820.72 & 90370511.1 \\
2027 & 336.26 & 121.17 & 463762.90 & 91475363.1 \\
2028 & 373.12 & 124.41 & 492367.12 & 92594126 \\
2029 & 461.27 & 124.96 & 522742.56 & 93727040.5 \\
2030 & 531.48 & 126.40 & 555003.34 & 94874219.8 \\
\hline
\end{tabular}

(Source: Own; Software Caterpillar SSA)

Table 7

Energy Consumption Estimation and Qualitative Input Variables Estimation

\begin{tabular}{|cccc|}
\hline Year & Consumption & $\begin{array}{c}\text { Construction } \\
\text { Methods }\end{array}$ & Usage Culture \\
\hline 2018 & {$[269658.4,271959.5]$} & $\mathrm{L}$ & $\mathrm{L}$ \\
2019 & {$[289776.6,292129.8]$} & $\mathrm{L}$ & $\mathrm{L}$ \\
2020 & {$[310919.7,313337.3]$} & $\mathrm{M}$ & $\mathrm{L}$ \\
2021 & {$[321969,324470.5]$} & $\mathrm{M}$ & $\mathrm{M}$ \\
2022 & {$[343028.3,345585.3]$} & $\mathrm{NH}$ & $\mathrm{M}$ \\
2023 & {$[373535.7,376181.2]$} & $\mathrm{NH}$ & $\mathrm{M}$ \\
2024 & {$[388949.4,391635.6]$} & $\mathrm{H}$ & $\mathrm{M}$ \\
2025 & {$[413816.2,416597.6]$} & $\mathrm{H}$ & $\mathrm{NH}$ \\
2026 & {$[456995.6,459910.1]$} & $\mathrm{H}$ & $\mathrm{NH}$ \\
2027 & {$[485630.2,488630.5]$} & $\mathrm{VH}$ & $\mathrm{NH}$ \\
2028 & {$[515822.2,518938.3]$} & $\mathrm{VH}$ & $\mathrm{H}$ \\
2029 & {$[574657.6,577961.4]$} & $\mathrm{VH}$ & $\mathrm{H}$ \\
2030 & {$[622703.6,626160.3]$} & $\mathrm{VVH}$ & $\mathrm{H}$ \\
\hline
\end{tabular}

$$
\begin{aligned}
& -398235+771 \text { Pr }_{t+1}+198 \text { Pro }_{t+1} \\
& +0.00708 P o_{t+1}-142 C M_{t+1} \\
& -2272 U C_{t+1} \\
& \leq-378323.25+732.45 \text { Pr }_{t} \\
& +188.1 \text { Pro }_{t}+0.006726 \mathrm{Po}_{t} \\
& -134.9 \mathrm{CM}_{t}-2158.4 U C_{t} \\
& -398477+771 \text { Pr }_{t+1}+162 \text { Pro }_{t+1} \\
& +0.00708 P o_{t+1}-142 C M_{t+1} \\
& -2272 U C_{t+1} \\
& \leq-378553+732.45 P r_{t} \\
& +188.1 \text { Pro }_{t}+0.006726 \mathrm{Po}_{t} \\
& -134.9 C_{t}-2158.4 U C_{t}
\end{aligned}
$$

Defining the deviation variables $d_{1}^{-}, d_{1}^{+}, d_{2}^{-}, d_{2}^{+}$; the goal programming based consumption optimisation model is formulated:

Min $d_{1}^{+}+d_{2}^{+}$S.T.

$$
\begin{aligned}
&-398235+771 P_{t+1}+198 \text { Pro }_{t+1}+0.00708 P o_{t+1} \\
&-142 \text { CM }_{t+1}-2272 U C_{t+1}+d_{1}^{-} \\
&-d_{1}^{+} \\
&=-378323.25+732.45 P r_{t} \\
&+188.1 \text { Pro }_{t}+0.006726 P o_{t} \\
&-134.9 \text { CM }_{t}-2158.4 U C_{t} \\
&-398477+771 P r_{t+1}+162 \text { Pro }_{t+1}+0.00708 P o_{t+1}-142 C M_{t+1}-2272 U C_{t+1}+d_{2}^{-} \\
&-d_{2}^{+} \\
&=-378553+732.45 \text { Pr }_{t} \\
&+188.1 \text { Pro }_{t}+0.006726 P o_{t} \\
&-134.9 \text { CM }_{t}-2158.4 U C_{t}
\end{aligned}
$$

(ii) $U C \in\{V L, L, M L, M, M H, H, V H\}$

(iii) $P o_{t+1} \geq(1+g r) P o_{t}$

(iv) $P r_{t+1} \geq\left(1+i_{t}\right) P r_{t}$, Pro $_{t+1} \geq$ Pro $_{t+1}$

The objective function of Eq. (20) seeks to minimise undesirable deviations from the considered goals of decreasing the amount of consumption to a value between $75 \%-95 \%$ of the current consumption. Constraints (i) and (ii) expressed the possible variation in two qualitative variables of construction method and usage culture. Eventually, constraint (iii) illustrated that the population of period $t+1$ could not be lower than the population at period $t$ when $g r$ is the growth rate of population from 1996 to 2015. Constraint (iv) illustrated that price at year $t+1$ is at least as large as the price at a period $t$ plus the expected inflation rate of the year that is illustrated by $i_{t}$. To solve the above model, first, two variables of $\mathrm{CM}$ and $\mathrm{UC}$ are substituted with the following equivalents:

$$
\begin{gathered}
C M=y_{1}+2 y_{2}+3 y_{3}+4 y_{4}+5 y_{5}+6 y_{6}+7 y_{7} \\
U C=y_{8}+2 y_{9}+3 y_{10}+4 y_{11}+5 y_{12}+6 y_{13}+7 y_{14}
\end{gathered}
$$

Where, $y_{1}, y_{8} \approx V L, \quad y_{2}, y_{9} \approx L, \quad y_{3}, y_{10} \approx M L, \quad y_{4}, y_{11} \approx M$, $y_{5}, y_{12} \approx M H, y_{6}, y_{13} \approx H, y_{7}, y_{14} \approx V H$.

Substituting above equivalents into the model (20), the following integer goal programming model is obtained:

$$
\begin{aligned}
& \text { Min } d_{1}^{+}+d_{2}^{+} \text {S.T. } \\
& -398235+771 \text { Pr }_{t+1}+198 \text { Pro }_{t+1}+ \\
& 0.00708 \mathrm{Po}_{t+1}-142\left(y_{1, t+1}+2 y_{2, t+1}+\right. \\
& 3 y_{3, t+1}+4 y_{4, t+1}+5 y_{5, t+1}+6 y_{6, t+1}+ \\
& \left.7 y_{7, t+1}\right)-2272\left(y_{8, t+1}+2 y_{9, t+1}+3 y_{10, t+1}+\right. \\
& \left.4 y_{11, t+1}+5 y_{12, t+1}+6 y_{13, t+1}+7 y_{14, t+1}\right)+d_{1}^{-}- \\
& d_{1}^{+}=-378323.25+732.45 \text { Pr }_{t}+188.1 \text { Pro }_{t}+ \\
& 0.006726 \mathrm{Po}_{t}-134.9\left(y_{1, t}+2 y_{2, t}+3 y_{3, t}+\right. \\
& \left.4 y_{4, t}+5 y_{5, t}+6 y_{6, t}+7 y_{7, t}\right)-2158.4\left(y_{8, t}+\right. \\
& \left.2 y_{9, t}+3 y_{10, t}+4 y_{11, t}+5 y_{12, t}+6 y_{13, t}+7 y_{14, t}\right) \\
& -398477+771 \text { Pr }_{t+1}+162 \text { Pro }_{t+1} \\
& +0.00708 \mathrm{Po}_{t+1} \\
& -142\left(y_{1, t+1}+2 y_{2, t+1}\right. \\
& +3 y_{3, t+1}+4 y_{4, t+1}+5 y_{5, t+1} \\
& \left.+6 y_{6, t+1}+7 y_{7, t+1}\right) \\
& -2272\left(y_{8, t+1}+2 y_{9, t+1}\right. \\
& +3 y_{10, t+1}+4 y_{11, t+1} \\
& +5 y_{12, t+1}+6 y_{13, t+1} \\
& \left.+7 y_{14, t+1}\right)+d_{2}^{-}-d_{2}^{+} \\
& =-378553+732.45 P r_{t} \\
& +188.1 \text { Pro }_{t}+0.006726 \mathrm{Po}_{t} \\
& -134.9\left(y_{1, t}+2 y_{2, t}+3 y_{3, t}\right. \\
& +4 y_{4, t}+5 y_{5, t}+6 y_{6, t} \\
& \left.+7 y_{7, t}\right) \\
& -2158.4\left(y_{8, t}+2 y_{9, t}+3 y_{10, t}\right. \\
& +4 y_{11, t}+5 y_{12, t}+6 y_{13, t} \\
& \left.+7 y_{14, t}\right) \\
& C M_{t} \leq C M_{t+1} \leq C M_{t}+1 \\
& U C_{t} \leq U C_{t+1} \leq U C_{t}+1 \\
& P o_{t+1} \geq(1+g r) P o_{t} \\
& P r_{t+1} \geq\left(1+i_{t}\right) \text { Pr }_{t}, \text { Pro }_{t+1} \geq \text { Pro }_{t+1}
\end{aligned}
$$

Solving the above model using Lingo package, the optimal solution can be obtained. Now, consider the case when $t=2016$. At this year, it is aimed that the consumption of 2016 is about $95 \%$ of the use of 2015 , i.e. $0.95 \times 555003.34=527253.2$. Furthermore, $C M_{2015}=$ 
Hannan Amoozad Mahdiraji, Moein Beheshti, Seyed Hossein Razavi Hajiagha, Zenonas Turskis. A Hybrid Fuzzy...

6, $U C_{2015}=4, \operatorname{Pr}_{2016}$ is predicted to be nearly 66.74, $\mathrm{Po}_{2016}$ is predicted to be at least 80032947.1. Solving the above model, the optimal consumption of the year 2016 eventuates as $y_{2,2016}^{*}=y_{9,2016}^{*}=1$, i.e. constructions method should be kept at high-level, while the usage culture should be improved to a very high level. Regarding other factors, the population is proposed to keep at 80032950, the price at 66.74 , and productivity improved to 121.24 . With this case in mind, the consumption is estimated at the interval [526770.1, 527495.1]. The model is constructed and solved for years from 2017 to 2020 employing a similar manner. The results are presented in Table 8 . The acquired data by optimisation are compared to the estimation methodology (34), the results are briefed in Table 9.

Table 8

Optimising the Consumption of Electricity in Iran from 2016 to 2020

\begin{tabular}{|c|c|c|c|c|c|c|}
\hline Year & Price & $\begin{array}{l}\text { Produc } \\
\text { tivity }\end{array}$ & Population & $\begin{array}{l}\text { Constru } \\
\text { ction } \\
\text { methods }\end{array}$ & $\begin{array}{l}\text { Usage } \\
\text { culture }\end{array}$ & $\begin{array}{l}\text { Consumpt } \\
\text { ion }\end{array}$ \\
\hline 2016 & 66.7 & 121.2 & 80032950 & Low & Low & $\begin{array}{l}526770.1, \\
527495.1]\end{array}$ \\
\hline 2017 & 80.5 & 121.2 & 81009700 & $\begin{array}{l}\text { Moderate } \\
\text { ly low }\end{array}$ & $\begin{array}{l}\text { Moderat } \\
\text { ely low }\end{array}$ & $\begin{array}{l}{[500637.3,} \\
501017.9]\end{array}$ \\
\hline 2018 & 83.0 & 121.2 & 81996473 & Medium & Medium & $\begin{array}{l}{[475545.2,} \\
475967]\end{array}$ \\
\hline 2019 & 104.1 & 121.2 & 82995080 & $\begin{array}{l}\text { Moderate } \\
\text { ly high }\end{array}$ & $\begin{array}{l}\text { Moderat } \\
\text { ely high }\end{array}$ & $\begin{array}{l}{[451685.7,} \\
452210.3]\end{array}$ \\
\hline 2020 & 130.3 & 1875.7 & 84006900 & High & High & $\begin{array}{l}{[429116.8,} \\
429592.6]\end{array}$ \\
\hline
\end{tabular}

Table 9

Comparing Methods for Consumption of Electricity in Iran from 2016 to 2020

\begin{tabular}{|lll|}
\hline Year & Estimation & Optimisation \\
\hline 2016 & {$[575149,602896]$} & {$[526770.1,527495.1]$} \\
2017 & {$[590236.2,622527.2]$} & {$[500637.3,501017.9]$} \\
2018 & {$[596824.3,633759.3]$} & {$[475545.2,475967]$} \\
2019 & {$[620254.8,657089.8]$} & {$[451685.7,452210.3]$} \\
2020 & {$[648559.1,685394.1]$} & {$[429116.8,429592.6]$} \\
\hline
\end{tabular}

As it can be seen from Table 8, if decision makers try to improve construction method and usage culture in a stepwise manner, i.e. construction method is developed from very low in 2015 to low $\rightarrow$ moderately low $\rightarrow$ medium $\rightarrow$ moderately high $\rightarrow$ high in next years, respectively, and usage culture is enhanced from very low similar to construction method, and the growth in price, population, and productivity is controlled on the basis of the predicted values; thus, the consumption will be diminished from its forecasted values. If the estimated value at time period $t$ is shown by $E s_{t}$ and the optimised method by $O p_{t}$, then the grey possibility degree (Li et al., 2007), that shows the degree of dominance of a grey number to another one, then it can be concluded that the optimised values are lower than estimated values with a $100 \%$ possibility.

Figure 4 indicates the interval plot of estimated (reported by E2016 - E2020) against optimised (indicated by $02016-02020$ ) values of consumption. It is clear that the mean and range of usage is decreased based on the optimised scenario.

\section{Conclusion}

Scheduling a specific approach to optimise the electricity consumption rate due to the scarce resources are considered in this research. In conjunction with the limitations of data gathering, the scarce annual datasheets and the native character of forecasting procedures causing an error, a novel SSA-fuzzy regression model was designed to minimise the possible negligence. Furthermore, a goal programming approach was developed and employed to solve the fuzzy-based mathematical model. Applying singular spectrum analysis for reconstructing time series, proposing a fuzzy regression approach for energy consumption estimation and designing a goal programming interval based model to optimise EC are the main highlights of this research. Based on this novel approach, policymaking in many infrastructural areas was proposed to organise power consumption in Iran. The case of Iran was chosen due to the lack of a monitoring framework and the large electrical consumption rate in recent years.

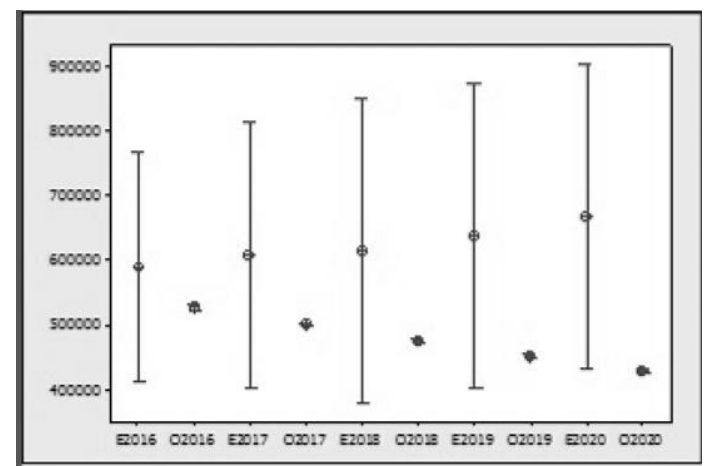

Figure 4. Interval Plot of Estimated Against Optimised Consumption

By investigating the relevant data to EC in the last two decades to forecast the EC for the next five years, an incremental pattern has resulted. A useful optimising model using fuzzy regression is presented to control the consumption.

Improvements in construction method and usage culture in a stepwise manner are found to be the solution for the next five years. Researchers can investigate cases from other countries or use a fuzzy singular spectrum analysis to forecast these factors in an uncertain situation. Moreover, researchers can implement the proper and rarely used SSAfuzzy regression framework to optimise other controversial variables. The results of this research are beneficial for governmental authorities in policymaking. Based on the findings emanated from the proposed optimisation method, the optimal amount of each dependent criteria to decrease nearly $30 \%$ of consumption rate are estimated; hence, policymaking is significantly facilitated.

\section{References}

Abdel-Aal, R. E. (2006). Modeling and forecasting electric daily peak loads using abductive networks. International Journal of Electrical Power and Energy Systems, 28(2), 133-141. https://doi.org/10.1016/j.ijepes.2005.11.006 
Abdollahzade, M., Miranian, A., Hassani, H., \& Iranmanesh, H. (2015). A new hybrid enhanced local linear neuro-fuzzy model based on the optimized singular spectrum analysis and its application for nonlinear and chaotic time series forecasting. Information Sciences, 295, 107-125. http://dx.doi.org/10.1016/j.ins.2014.09.002

Abdullah, L., \& Zamri, N. (2012). Road accident models with two threshold levels of fuzzy linear regression. Journal of Emerging Trends in Computing and Information Sciences, 3(2), 225-230.

Arabzad, S. M., Ghorbani, M., \& Hashemkhani Zolfani, S. (2015). A multi-objective robust optimization model for a facility location-allocation problem in a supply chain under uncertainty. Inzinerine Ekonomika-Engineering Economics, 26(3), 227-238. http://dx.doi.org/10.5755/j01.ee.26.3.4287

Arulchinnappan, S., \& Rajendran, G. (2011). A study on reverse osmosis permeating treatment for yarn dyeing effluent using fuzzy linear regression model. African Journal of Biotechnology, 17969-17972.

Bagocius, V., Zavadskas, E. K., \& Turskis, Z. (2014). Multi-person selection of the best wind turbine based on the multicriteria integrated additive-multiplicative utility function. Journal of Civil Engineering and Management, 20(4), 590599. https://doi.org/10.3846/13923730.2014.932836

Beneki, C., Eeckels, B., \& Leon, C. (2012). Signal extraction and forecasting of the UK tourism income time series: A singular spectrum analysis approach. Journal of Forecasting, 31(5), 391-400. https://doi.org/10.1002/for.1220

Bozzo, E., Carniel, R., \& Fasino, D. (2010). Relationship between Singular Spectrum Analysis and Fourier analysis: Theory and application to the monitoring of volcanic activity. Computers \& Mathematics with Applications, 60(3), 812-820. https://doi.org/10.1016/j.camwa.2010.05.028

Broomhead, D. S., \& King, G. P. (1986). Extracting qualitative dynamics from experimental data. Physica D: Nonlinear Phenomena, 20(2-3), 217-236. https://doi.org/10.1016/0167-2789(86)90031-X

Buckley, J. J., \& Eslami, E. (2002). An Introduction to Fuzzy Logic and Fuzzy Sets. Physica-Verlag, Heidelberg, Germany. doi:10.1007/978-3-7908-1799-7

Buhari, M., \& Adamu, S. S. (2012). Short-term load forecasting using Artificial Neural Network. In Proceedings of the International Multi-Conference of Engineers and Computer Scientists, Vol 1.

Canyurt, O. E., Ozturk, H. K., Hepbasli, A., \& Utlu, Z. (2007). Modeling and application of genetic algorithm (GA) approach to estimating the future total energy input values. Energy Sources, Part A, 29(10), 861-871. https://doi.org/10.1080/15567240500400929

Carniel, R., Barazza, F., \& Pascolo, P. (2006). Improvement of Nakamura technique by singular spectrum analysis. Soil Dynamics and Earthquake Engineering, 26(1), 55-63. https://doi.org/10.1016/j.soildyn.2005.08.005

Chang, Y.-W., Van Bang, P., \& Loh, C.-H. (2015). Identification of Basin Topography Characteristic Using Multivariate Singular Spectrum Analysis: Case Study of the Taipei Basin. Engineering Geology, 197, $240-252$. https://doi.org/10.1016/j.enggeo.2015.08.027

Chatterjee, P., Mondal, S., Boral, S., Banerjee, A., \& Chakraborty, S. (2017). A novel hybrid method for non-traditional machining process selection using factor relationship and Multi-Attributive Border Approximation Method. Facta Universitatis, Series: Mechanical Engineering, 15(3), 439-456. https://doi.org/10.22190/FUME170508024C

Chen, F., Chen, Y., Zhou, J., \& Liu, Y. (2016). Optimizing h value for fuzzy linear regression with asymmetric triangular fuzzy coefficients. Engineering Applications of Artificial Intelligence, 47, 16-24. https://doi.org/10.1016/j.enga ppai.2015.02.011

Chen, S. J., \& Chen, S. M. (2007). Fuzzy risk analysis based on the ranking of generalized trapezoidal fuzzy numbers. Applied Intelligence, 26(1), 1-11. https://doi.org/10.1007/s10489-006-0003-5

Chen, Y., Tang, J., Fung, R. Y. K., \& Ren, Z. (2004). Fuzzy regression-based mathematical programming model for quality function deployment. International Journal of Production Research, 42(5), 1009-1027. https://doi.org/10.1080/0020 7540310001619623

Chu, M. T., Lin, M. M., \& Wang, L. (2014). A study of singular spectrum analysis with global optimization techniques. Journal of Global Optimization, 60(3), 551-574. https://doi.org/10.1007/s10898-013-0117-3

Delgado, M., Vila, M. A., \& Voxman, W. (1998). On a canonical representation of fuzzy numbers. Fuzzy Sets and Systems, 93(1), 125-135. https://doi.org/10.1016/S0165-0114(96)00144-3

Einstein, A. (1961). Relativity: The Special and the General Theory (3rd ed.). New York, NY: Three Rivers Press.

García Plaza, E., \& Núnez Lopez, P. J. (2017). Surface roughness monitoring by singular spectrum analysis of vibration signals. Mechanical Systems and Signal Processing, 84, 516-530. https://doi.org/10.1016/j.ymssp.2016.06.039

Ghaderi, F., Mohseni, H. R., \& Sanei, S. (2011). Localizing heart sounds in respiratory signals using singular spectrum analysis. IEEE Transactions on Biomedical Engineering, 58(12), 3360-3367. https://doi.org/10.1109/TBM E.2011.2162728 
Hannan Amoozad Mahdiraji, Moein Beheshti, Seyed Hossein Razavi Hajiagha, Zenonas Turskis. A Hybrid Fuzzy...

Ghanati, R., Hafizi, M. K., Mahmoudvand, R., \& Fallahsafari, M. (2016). Filtering and parameter estimation of surfaceNMR data using singular spectrum analysis. Journal of Applied Geophysics, 130, 118-130. https://doi.org/10.10 16/j.jappgeo.2016.04.005

Ginevicius, R. (2011). A new determining method for the criteria weights in multicriteria evaluation. International Journal of Information Technology \& Decision Making, 10(6), 1067-1095. https://doi.org/10.1142/S0219622011004713

Ginevicius, R., Gedvilaite, D., \& Stasiukynas, A. (2018). Impact of economic development on the ecology in the regions of Lithuania. Economics and Management, 21(2), 21-37. https://doi.org/10.15240/tul/001/2018-2-002

Ginevicius, R., Gedvilaite, D., Stasiukynas, A., \& Sliogeriene, J. (2018). Quantitative assessment of the dynamics of the economic development of socioeconomic systems based on the MDD method. Inzinerine Ekonomika-Engineering Economics, 29(3), 264-271. https://doi.org/10.5755/j01.ee.29.3.20444.

Golyandina, N., \& Korobeynikov, A. (2014). Basic Singular Spectrum Analysis and forecasting with R. Computational Statistics \& Data Analysis, 71, 934-954. https://doi.org/10.1016/j.csda.2013.04.009

Grzegorzewski, P. (1998). Metrics and orders in space of fuzzy numbers. Fuzzy Sets and Systems, 97(1), 83-94. https://doi.org/10.1016/S0165-0114(96)00322-3

Hassani, H. (2007). Singular Spectrum Analysis: Methodology and Comparison. Journal of Data Science, 5, $239-257$. https://doi.org/10.3189/172756506781828863

Hassani, H., \& Mahmoudvand, R. (2013). Multivariate singular spectrum analysis: a general view and new vector forecasting approach. International Journal of Energy and Statistics, 1(01), 55-83. https://doi.org/10.114 2/S2335680413500051

Hashemkhani Zolfani, S., Zavadskas, E. K., \& Turskis, Z. (2013). Design of products with both International and Local perspectives based on Yin-Yang balance theory and SWARA method. Economic Research-Ekonomska Istraživanja, 26(2), 153-166. https://doi.org/10.1080/1331677X.2013.11517613

Heilpern, S. (1992). The expected value of a fuzzy number. Fuzzy Sets and Systems, 47(1), 81-86. https://doi.org/10.1016/0165-0114(92)90062-9

Jugend, D., Figueiredo, J., \& Pinheiro, M. A. P. (2017). Environmental sustainability and product portfolio management in biodiversity firms: A comparative analysis between Portugal and Brazil. Contemporary Economics, 11(4), 431442. https://doi.org/10.5709/ce.1897-9254.254.

Karaulova, T., \& Bashkite, V. (2016). Decision-making framework for used industrial equipment. Inzinerine EkonomikaEngineering Economics, 27(1), 23-31. https://doi.org/10.5755/j01.ee.27.1.8618

Kermanshahi, B. (1998). Recurrent neural network for forecasting next 10 years loads of nine Japanese utilities. Neurocomputing, 23(1/3), 125-133. https://doi.org/10.1016/S0925-2312(98)00073-3

Kermanshahi, B., \& Iwamiya, H. (2002). Up to year 2020 load forecasting using neural nets. International Journal of Electrical Power \& Energy Systems, 24(9), 789-797. https://doi.org/10.1016/S0142-0615(01)00086-2

Kumar, A., \& Gupta, A. (2011). Methods for solving fuzzy assignment problems and fuzzy travelling salesman problems with different membership functions. Fuzzy Information and Engineering, 3(1), 3-21. https://doi.org/10.1007/s12543011-0062-0

Maddirala, A. K., \& Shaik, R. A. (2016). Motion artifact removal from single channel electroencephalogram signals using singular spectrum analysis. Biomedical Signal Processing and Control, 30, 79-85. https://doi.org/10.101 6/j.bspc.2016.06.017

Mahdiraji, H. A., Hajiagha, S. H., Hashemi, S. S., \& Zavadskas, E. K. (2016). A grey multi-objective linear model to find critical path of a project by using time, cost, quality and risk parameters. E+M Ekonomie a Management, 19(1), 4961. https://doi.org/10.15240/tul/001/2016-1-004

Masulli, F., Mitra, S., \& Pasi, G. (Eds.). (2007). Applications of Fuzzy Sets Theory: 7th International Workshop on Fuzzy Logic and Applications, WILF 2007, Camogli, Italy, July 7-10, 2007, Proceedings (Vol. 4578). Springer Science \& Business Media.

Medineckiene, M., Zavadskas, E. K., Björk, F., \& Turskis, Z. (2015). Multi-criteria decision-making system for sustainable building assessment/certification. Archives of Civil and Mechanical Engineering, 15(1), 11-18. https://doi.org/10.10 16/j.acme.2014.09.001

Muzzioli, S., Ruggier, A., \& Debaets, B. (2015). A comparison of fuzzy regression methods for the estimation of the implied volatility smile function. Fuzzy Sets and Systems, 266, 131-143. https://doi.org/10.1016/j.fss.2014.11.015

Ozturk, H. K., Canyurt, O. E., Hepbasli, A., \& Utlu, Z. (2004). Residential-commercial energy input estimation based on genetic algorithm (GA) approaches: An application of Turkey. Energy and Buildings, 36(2), $175-183$. https://doi.org/10.1016/j.enbuild.2003.11.001 
Pampuri, L., Cereghetti, N., Strepparava, D., \& Caputo, P. (2016). Analysis of the electricity consumptions: A first step to develop a district cooling system. Sustainable Cities and Society, 23, 23-36. https://doi.org/10.1016/j.scs.2016.02.015

Pike, E. R., McWhirter, J. G., Bertero, M., \& de Mol, C. (1984). Generalised information theory for inverse problems in signal processing. IEE Proceedings F Communications, Radar and Signal Processing, 131(6), 660-667. https://doi.org/10.1049/ip-f-1.1984.0100

Pamucar, D., \& Cirovic, G. (2015). The selection of transport and handling resources in logistics centers using MultiAttributive Border Approximation Area Comparison (MABAC). Expert Systems with Applications, 42(6), 30163028. https://doi.org/10.1016/j.eswa.2014.11.057

Planning, B. O. (2011). Iran Energy Balance. Tehran: Ministry of Energy.

Pourazarm, E., \& Cooray, A. (2013). Estimating and forecasting residential electricity demand in Iran. Economic Modelling, 35, 546-558. https://doi.org/10.1016/j.econmod.2013.08.006

Pushpa B., \& Vasuki, R. (2013). A least absolute approach to multiple fuzzy regression using TW-norm based operations. International Journal of Fuzzy Logic Systems, 3(2), 73-84. https://doi.org/10.5121/ijfls.2013.3206

Razavi Hajiagha, S. H., Mahdiraji, H. A., Hashemi, S. S., \& Turskis, Z. (2015). Determining weights of fuzzy attributes for multi-attribute decision-making problems based on consensus of expert opinions. Technological and Economic Development of Economy, 21(5), 738-755. https://doi.org/10.3846/20294913.2015.1058301

Razavi, S. H., Amoozad, H., Zavadskas, E. K., \& Hashemi, S. S. (2013). A Fuzzy Data Envelopment Analysis approach based on parametric programming. International Journal of Computers Communications \& Control, 8(4), 594-607. https://doi.org/10.15837/ijccc.2013.4.580

Ruiz Estrada, M. A., Chandran, V., \& Tahir, M. (2016). An introduction to the multidimensional real-time economic modeling. Contemporary Economics, 10(1) 55-70. https://doi.org/10.5709/ce.1897-9254.198

Saparauskas, J., Zavadskas, E. K., \& Turskis, Z. (2011). Selection of facade's alternatives of commercial and public buildings based on multiple criteria. International Journal of Strategic Property Management, 15(2), $189-203$. https://doi.org/10.3846/1648715X.2011.586532

Shafi, A. M., \& Rusiman, M. S. (2015). The use of fuzzy linear regression models for tumor size in colorectal cancer in hospital of Malaysia. Applied Mathematical Sciences, 9(56), 2749-2759. https://doi.org/10.12988/ams.2015.5175

Shiu, A., \& Lam, P.-L. (2004). Electricity consumption and economic growth in China. Energy Policy, 32(1), $47-54$. https://doi.org/10.1016/S0301-4215(02)00250-1

Szomolanyi, K., Lukacik, M., \& Lukacikova, A. (2017). Business cycles in European post-communist countries. Contemporary Economics, 11(2), 171-186. https://doi.org/10.5709/ce.1897-9254.235.

Skare, M., \& Stjepanovic, S. (2016). Measuring Business Cycles: A Review. Contemporary Economics, 10(1), 83-94. https://doi.org/10.5709/ce.1897-9254.200

Streimikiene, D., Sliogeriene, J., \& Turskis, Z. (2016). Multi-criteria analysis of electricity generation technologies in Lithuania. Renewable Energy, 85, 148-156. https://doi.org/10.1016/j.renene.2015.06.032

Tanaka, H., Uejima, S., \& Asai, K. (1982). Linear regression analysis with fuzzy model. IEEE Transactions on Systems, 12(6), 903-907. https://doi.org/10.1109/TSMC.1982.4308925

Taujanskaite, K., Milcius, E., \& Rutkauskas, A. V. (2015). Integrated cross disciplinary approach to household expenditure management. Inzinerine Ekonomika-Engineering Economics, 26(5), 489-499. https://doi.org/10.5755/j01.ee.26 .5 .13066

Tunc, M., Camdali, U., Liman, T., \& Deger, A. (2006). Electrical energy consumption and production of Turkey versus world. Energy Policy, 34(17), 3284-3292. https://doi.org/10.1016/j.enpol.2005.06.023

Ubale, A. B., \& Sananse, S. L. (2015). Fuzzy Regression Model and Its Application: A Review. International Journal of Innovative Research in Science, Engineering and Technology, 4(11), 10853-10860. https://doi.org/10.15680/IJIR SET.2015.0411086.

Wang, P. P. (Ed.) (1983). Advances in Fuzzy Sets, Possibility Theory, and Applications. Plenum Press, New York. doi:10.1007/978-1-4613-3754-6.

Wu, H. C. (2003). Fuzzy estimates of regression parameters in linear regression models for imprecise input and output data. Computational Statistics \& Data Analysis, 42(1), 203-217. https://doi.org/10.1016/S0167-9473(02)00116-0.

Xiao, Y., Liu, J. J., Hu, Y., Wang, Y., Lai, K. K., \& Wang, S. (2014). A neuro-fuzzy combination model based on singular spectrum analysis for air transport demand forecasting. Journal of Air Transport Management, 39, 1-11. https://doi.org/10.1016/j.jairtraman.2014.03.004 
Hannan Amoozad Mahdiraji, Moein Beheshti, Seyed Hossein Razavi Hajiagha, Zenonas Turskis. A Hybrid Fuzzy...

Zadeh, L. (1965). Fuzzy sets. Information and Control, 8(3), 338-353. https://doi.org/10.1016/S0019-9958(65)90241-X

Zavadskas, E. K., Kaklauskas, A., Turskis, Z., \& Kalibatas, D. (2009). An approach to multi-attribute assessment of indoor environment before and after refurbishment of dwellings. Journal of Environmental Engineering and Landscape Management, 17(1), 5-11. https://doi.org/10.3846/1648-6897.2009.17.5-11

Zavadskas, E. K., Turskis, Z., \& Antucheviciene, J. (2015a). Selecting a contractor by using a novel method for multiple attribute analysis: Weighted Aggregated Sum Product Assessment with grey values (WASPAS-G). Studies in Informatics and Control, 24(2), 141-150. https://doi.org/10.24846/v24i2y201502

Zavadskas, E. K., Turskis, Z., \& Antucheviciene, J. (2015b). Selecting a contractor by using a novel method for multiple attribute analysis: Weighted Aggregated Sum Product Assessment with grey values (WASPAS-G). Studies in Informatics and Control, 24(2), 141-150. https://doi.org/10.24846/v24i2y201502

Zavadskas, E. K., Turskis, Z., \& Bagocius, V. (2015c). Multi-criteria selection of a deep-water port in the Eastern Baltic Sea. Applied Soft Computing, 26, 180-192. https://doi.org/10.1016/j.asoc.2014.09.019

Ziemianczyk, U., Krakowiak-Bal, A., \& Peszek, A. (2017). Sharing of knowledge as a condition of rural area developmentFuzzy-set qualitative comparative analysis approach. Contemporary Economics, 11(4), 471-478, https://doi.org/10.5 709/ ce.1897-9254.257

Zhigljavsky, A. (2011). Singular spectrum analysis for time series. In International Encyclopedia of Statistical Science, 1335-1337. Springer Berlin Heidelberg. https://doi.org/10.1007/978-3-642-04898-2_521

Zimmermann, H. -J. (1978). Fuzzy programming and linear programming with several objective functions. Fuzzy Sets and Systems, 1(1), 45-55. https://doi.org/10.1016/0165-0114(78)90031-3

The article has been reviewed.

Received in June 2018; accepted in April 2019. 